\title{
Evaluación de metodologías de planeación estratégica en pymes del sector confección: estudio de caso *
}

\author{
Evaluation of Strategic Planning Methodologies at SMEs in the Clothing Sector: \\ A Case Study
}

\section{Edwin Octavio Ciro-Gallo}

Estudiante Maestría en Administración, Universidad de Antioquia, Medellín-Colombia,edwin.ciro@udea.edu.co

\author{
Cómo citar / How to cite \\ Ciro-Gallo, E. O. (2021). Evaluación de metodologías de planeación estratégica en pymes del sector confección: \\ estudio de caso. Revista CEA, v. 7, n. 13, e1634. https://doi.org/10.22430/24223182.1634
}

Recibido: 15 de julio de 2020

Aceptado: 27 de octubre de 2020

\section{Resumen}

En el marco de la complejidad que presentan las pymes en su contexto actual, la evaluación de metodologías de planeación estratégica se ha convertido en una herramienta efectiva en la búsqueda de soluciones estratégicas que le permitan ser más rentables y competitivas. Bajo esta perspectiva, este artículo propone la evaluación de una metodología de planeación en una pyme del sector confección en Antioquia. El desarrollo metodológico se ejecutó en 3 fases: diagnóstico inicial, diagnóstico de variables micro - macroeconómicas y marco misional y estratégico. La información se obtuvo mediante entrevistas semiestructuradas a empleados y directivos, y a la observación directa. Los resultados indicaron que la gestión en la planeación no es la más adecuada y radica en el desconocimiento de un modelo eficiente y el poco interés directivo. Además, la evaluación mostró que la herramienta es viable cuando la empresa construye el proceso de planeación. Se detectó que, de acuerdo al constante cambio que presentan las pymes, es preciso la realización de investigaciones de tipo longitudinal que permitan diseñar metodologías que se adapten a su estructura actual. Los modelos de planeación que estén enmarcados a su contexto real, consolidan en mayor nivel la estructuración administrativa y la generación de ventajas competitivas. La herramienta está en función del análisis de factores internos y externos.

Palabras clave: método de planificación, gestión industrial, evaluación metodológica, pymes, planificación estratégica, competitividad.

\footnotetext{
* Este artículo se deriva del proyecto de trabajo de grado de Ingeniería de Producción titulado «Evaluación de una metodología para la planeación estratégica en una pyme del sector confección del departamento de Antioquia: estudio de caso - ITM 2018» y ha sido financiado con recursos propios.
} 
Clasificación JEL: L10, M10, M21.

\begin{abstract}
In the complexity of SMEs in their current context, evaluating strategic planning methodologies has been an effective tool to find strategic solutions that enable them to be more profitable and competitive. Therefore, this article evaluates a strategic planning methodology at an SME in the clothing sector in Antioquia, Colombia. Such evaluation was implemented in 3 stages: initial diagnosis, diagnosis of micro and macroeconomic variables, and mission and strategic framework. Semistructured interviews with employees and managers as well as direct observation were used to collect information. The results indicate that their management of strategic planning is not the most adequate due to a lack of knowledge about an efficient model and managers' little interest. Additionally, the evaluation showed that the tool can be implemented when the company defines its strategic planning. As a result of the constant changes SMEs undergo, cross-sectional studies should be conducted to design methodologies that can be adapted to their current structure. Planning models framed in their real context more greatly consolidate managerial structures and generate more competitive advantages. The tool is defined by internal and external factors.
\end{abstract}

Keywords: Planning method, industrial management, methodological evaluation, SMEs, strategic planning, competitiveness.

JEL classification: L10, M10, M21.

\title{
1. INTRODUCCIÓN
}

En relación con las pymes, la normatividad en Colombia en cuanto a la definición y clasificación de las micro, pequeñas, medianas y grandes empresas ha presentado ajustes de acuerdo a la ley 905 de 2004 y 1450 de 2011 (artículo 43), determinando que las microempresas cuentan con un número inferior a 10 empleados y activos totales de hasta 500 salarios mínimos legales vigentes (SMLV). Por su parte, las pequeñas empresas, cuentan con una planta de personal entre 11 y 50 empleados y activos entre 501 y 5.000 SMLV. Las medianas empresas, con un número de empleados entre 51 y 200 y activos entre 5.001 y 30.000 SMLV. Finalmente, las grandes empresas cuentan con más de 200 empleados y activos totales superiores a 30.001 SMLV. (Mora-Riapira et al., 2015).

De acuerdo con lo anterior, las empresas antioqueñas del sector confección pertenecientes a esta tipología, no utilizan la planeación estratégica (en adelante PE) como herramienta funcional que permite, mediante un análisis detallado de los procesos de la organización y de su macroentorno, definir e implementar estrategias orientadas al cumplimiento de los objetivos establecidos. Esto se presenta debido a que se ha considerado que la herramienta es sólo utilizada en la gran empresa (Kotler \& Armstrong, 2008). Y pese a que la PE es considerada una práctica empresarial popular, especialmente en el contexto de las pymes (Brinckmann et al., 2019), se desconoce una metodología que se adapte a estas empresas en particular para su aplicación. Más aun, las organizaciones de esta denominación generalmente tienen limitaciones como ausencia de redes cooperativas, crecimiento en el mercado, capacidades y recursos (Marqués \& Gama, 2020), y presentan carencias con respecto a un análisis global de su entorno para la identificación de variables relacionadas a los procesos 
internos y externos, las cuales conducen a la elaboración de un plan estratégico integral que las conlleve a tener una estructura misional y estratégica.

Por consiguiente, se destaca la imperiosa necesidad de evaluar una metodología definida de PE (Vargas Vallecilla, 2008) en una pyme del sector confección para constatar la validez de la herramienta y conocer los resultados de los análisis que se proponen en los numerales del 1 al 5 , al igual que los efectos del desarrollo de los numerales del 6 al 9 en el establecimiento de lineamientos estratégicos y misionales, articulando de esta forma los procesos internos en la identificación de sus variables y considerando, asimismo, los factores externos en la elaboración del plan para la estructuración de la organización, y en esta medida determinar si el modelo propuesto se adapta a las pymes de acuerdo a su normatividad y complejidad en el contexto actual. Además, conocer las causas por las cuales la empresa no aplica el proceso de PE como herramienta de gestión que tiene como propósito direccionar a la organización al logro de su plan integral, concentrando sus recursos hacia una misma dirección, entendiendo como premisa que el éxito estratégico requiere convertir los planes en acciones en la generación de valor (Serrano Cárdenas et al., 2013).

En efecto, la investigación en cuanto a PE surge, en principio, del interés por conocer procesos metodológicos existentes para el direccionamiento estratégico de las organizaciones y, en segunda medida, la pertinencia de evaluar una alternativa dinámica de acuerdo con las características de la pyme de este sector en particular que no cuenta con la herramienta, logrando que la empresa adopte un modelo más eficiente para su aplicación y, por medio de una metodología práctica, pueda consolidar su estructura organizacional y desarrollar un plan de acción que la direccione al logro de sus objetivos, los cuales son usados como mecanismo para la toma de decisiones (Basco, 2017) y conducentes a que la organización sea, en mayor proporción, más sostenible y competitiva en el mercado. En el presente estudio se identifican los principales factores asociados a la implementación del proceso de PE en la pyme, como también los aspectos que analizan las empresas en su situación actual como referente para el proceso de planeación. Finalmente, se identifican las etapas involucradas en el proceso de PE y se conoce la validez de la herramienta en la construcción de los lineamientos: misional y estratégico.

En esta dirección, el estudio de caso tiene la siguiente estructura: en la sección uno se presenta la introducción; en la dos se expone el marco teórico; la tercera se refiere a la metodología aplicada; la cuarta pone a consideración los resultados obtenidos del caso de estudio; la quinta expone la discusión; y, finalmente, en la sexta se presentan las conclusiones y se señalan las futuras líneas de investigación en el campo de la evaluación y aplicación de la herramienta organizacional.

\section{MARCO TEÓRICO}

\section{Concepto y evolución de planeación estratégica en la pyme}

La PE ha evolucionado en cuanto a la terminología empleada, el enfoque que han tomado las variables relacionadas con el entorno interno - externo y las características del proceso (Donkor et al., 2018). A partir de la trascendencia, tanto teórica como aplicada, se consolida la formalidad de la herramienta organizacional como instrumento que posteriormente es implementado por las organizaciones que tienen un enfoque empírico y, como resultado de un proceso de adaptabilidad, 
se definen las características generales para la estructuración organizacional (López Salazar, 2005; Mora-Riapira, 2015). Lo anterior indica que la PE ha desempeñado un papel importante en el fomento y ejecución de alternativas formales para el mejoramiento de las capacidades administrativas en las pequeñas y medianas empresas (pymes) (López Salazar, 2005; Valencia Maldonado \& Erazo, 2016; Grajales-Gaviria \& Castellanos-Polo, 2018). Los estudios realizados en los últimos años sobre este concepto han experimentado un crecimiento considerable (Ortiz García Navas et al., 2019), donde se destaca categóricamente la trascendencia e interés en esta disciplina. En este orden de ideas, y conociendo la evolución de la metodología, es preciso conocer su significado, estructura y utilidad. La estrategia, en un contexto amplio, se define como la fijación de metas y objetivos de una organización a largo plazo, los planes de acción a ejecutar y la asignación de recursos imprescindibles para el logro de dichas metas (Contreras Sierra, 2013). Representa, de manera clásica, la parte de la alta dirección de las empresas.

La PE es comprendida y empleada por los dirigentes para definir y estructurar con sentido lógico las orientaciones periódicas de la organización, y para direccionar los medios necesarios (Aktouf \& Suárez, 2012). En el mismo sentido, su formulación y puesta en marcha impactan en la visualización de planes que se implementan para aumentar la competitividad y demás objetivos organizacionales como son: la supervivencia, generación de utilidades y crecimiento, donde la misión es considerada un instrumento importante para la implementación de la estrategia (Rey \& Bastons, 2018) y, según Kalenatic et al., (2013) se debe definir y analizar para establecer los sistemas de apoyo estratégico. Es así como la PE es la formulación, ejecución y evaluación de acciones que le permiten a una organización el logro de sus objetivos (López Salazar, 2005), o como bien lo define Aktouf y Suárez, (2012) «proyecto elaborado que conlleva un conjunto ordenado de operaciones destinado a lograr un objetivo» (p.68).

Una vez interiorizado el concepto y entendido que la estrategia es el pilar que soporta el proceso de planeación, se pretende que ambos conceptos se conjuguen para formular los planes de acción que darán respuesta a los objetivos planteados por la pyme (Serrano Cárdenas et al., 2013; Haase \& Franco, 2016). Además de la investigación, se hace, más que interesante, necesario el aporte que se realiza en cuanto a la incorporación de los términos: recursos, acciones, organización y entorno, como elementos imprescindibles en la construcción de la estrategia, la cual deber estar alineada con la misión y los valores y principios corporativos (Pla-Barber et al., 2017). En esta medida la PE requiere la priorización de los problemas, la definición y evaluación de las posibles soluciones, la asignación de responsabilidades y recursos para efectuar dichas soluciones y hacer la evaluación continua de la implementación de las mismas (Serrano Cárdenas et al., 2013).

Es así como la herramienta metodológica y estratégica se relaciona con las decisiones que se adoptan respecto a la misión organizacional y a la identificación y análisis de las variables en la construcción de la matriz DOFA (Debilidades, Oportunidades, Fortalezas y Amenazas) como método efectivo para tener un referente claro respecto al contexto actual de la pyme (Frantz et al., 2017) y para estar en formulación constante de nuevas estrategias. La herramienta es un proceso continuo que inicia formulando las metas estratégicas y, posterior a ello, la ejecución y evaluación continua de los planes de acción desarrollados para dar cumplimiento a los objetivos estipulados.

Lo que refiere a la incorporación de ambos conceptos se define como la formulación, ejecución y evaluación de acciones que le permitan a una organización el logro de sus objetivos (David, 2003; 
Gerstgrasser \& Fiedler, 2016). En este sentido, la formulación incluye todo el componente misional; por tanto, en la implementación se desarrolla el enfoque estratégico, y finalmente en la evaluación se revisa el resultado de la estrategia (Blomqvist et al., 2015). Según lo anterior, puede decirse que para formular una estrategia se requiere identificar los factores que circundan dentro del ambiente interno de la organización, que son las debilidades - fortalezas y determinar, del mismo modo, las oportunidades - amenazas en el ambiente externo, además de establecer la misión, la visión, las políticas y los objetivos (de Jorge Moreno et al., 2010). De conformidad con lo anterior, en la construcción de la PE, cualquiera que fuere su estructura metodológica en el contexto pyme, Cisneros et al., (2011), proponen como modelo cuatro prioridades que pueden combinarse equilibradamente para el logro estratégico: i) tener una misión sustantiva y a largo plazo, ii) utilizar un modelo independiente en la dirección, iii) conseguir conexiones efectivas con partners estratégicos donde haya acuerdos de beneficio mutuo, iv) fomentar una cultura que impulse al personal al cumplimiento de la misión.

En consecuencia, la estrategia en el marco de la PE debe contar con un nivel adecuado de flexibilidad e integración (Ojha et al., 2020), no debe quedarse en un documento, es necesario ser ejecutada. No sirven mucho los planes más acertados y las estrategias más elaboradas si no se prevén, en concreto, las herramientas que permitan darles seguimiento y asegurar que lo realizado vaya en dirección al cumplimiento de los objetivos y la misión corporativa (Aktouf \& Suárez, 2012). Para lograrlo se requiere que la empresa asigne los recursos necesarios para que la estrategia formulada pueda llevarse a cabo de forma exitosa.

Al tener claro el concepto, es preciso conocer cómo ha evolucionado la aplicación de la herramienta organizacional en el contexto de las pymes. Es así como durante años se ha considerado que la PE es sólo para las macroempresas. Kotler y Armstrong (2008) hacen una somera mención de su importancia en la pequeña empresa, y establece los pasos para desarrollarla (Figura 1). Sin embargo, no define el procedimiento a seguir para la construcción, implementación y evaluación. Asimismo, para Tarapuez et al., (2016), la PE es una disciplina poco utilizada por las pymes, no obstante, en algunos casos, se da especialmente en las medianas empresas exportadoras. Empero, para fortuna del sector productivo representado por pequeñas y medianas empresas, que tienen una visión clara de negocio, es considerada una herramienta administrativa para empresas de cualquier sector de la economía sin importar su denominación y busca, a través del análisis de los factores internos y externos de su entorno, encontrar estrategias efectivas que permitan el cumplimiento de los objetivos, (Vargas Vallecilla, 2008). En la misma dirección, el resultado óptimo de la aplicación de la metodología organizacional va a depender del tamaño de la organización (Castaño Ramírez, 2010). La diferencia radica en principio, por el pensamiento del personal directivo en conformidad con su formalidad e informalidad y, de otro lado, en el modo como adopta la estrategia. Se puede afirmar que en ambos casos la PE se da en las pymes y grandes empresas de forma implícita y explicita, respectivamente. 


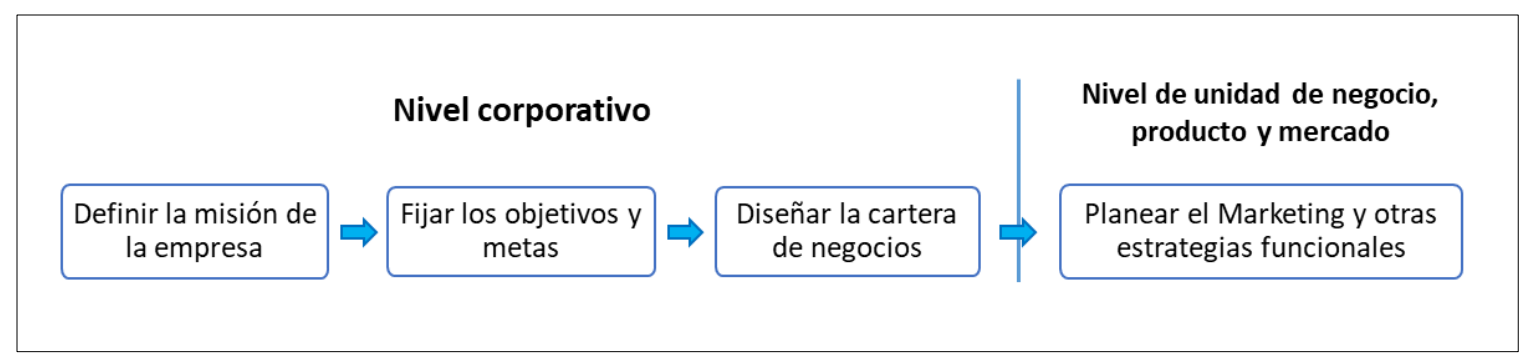

Figura 1. Etapas para desarrollar planeación estratégica

Figure 1. Stages to implement strategic planning

Fuente: elaboración propia a partir de fundamentos de marketing (Kotler \& Armstrong, 2008).

El tamaño de la empresa, así como su capacidad de producción, infraestructura, capital y maquinaria, no va a representar una ventaja frente a las pymes que no cuenten con los recursos mencionados, puesto que la aplicación de herramientas administrativas se ve altamente condicionadas por la personalidad y estilo de dirección de los empresarios. Aunque esto describe que la PE puede aplicarse a cualquier tipo de organización. Las empresas se ven expuestas a determinado grado de incertidumbre en su ambiente externo, por lo que no resulta adecuado desarrollar estrategias explicitas debido a que bloquean la visión global del entorno y, por tanto, el espíritu innovador del empresario no sobresale (López Salazar, 2005). Además, las empresas presentan contrariedad en la mejora de sus capacidades competitivas donde los datos más críticos se evidencian en la PE (Barriga Manrique, 2006).

Ahora, la herramienta administrativa puede ser objeto de imitación o sustitución de la información por parte de otras empresas por la forma como está estructurada, por consiguiente, la posibilidad de que represente una ventaja competitiva es baja (López Salazar, 2005). Castaño Ramírez (2010) se suma al argumento y sostiene que el éxito comercial de una organización no va a depender de la aplicación de un proceso de PE, puesto que está sujeta al contexto cultural y geográfico y se ve evidenciado en la forma como los empresarios toman las decisiones a partir de la consolidación y aplicación de una estrategia, la cual da cumplimiento a un objetivo específico enmarcado en un determinado entorno cultural. La controversia se manifiesta porque se difiere de los conceptos, los elementos que constituyen la herramienta, y su forma de operar. Esta polémica ha surgido por la falta de una base teórica que fundamente el análisis de las pymes (Castaño Ramírez, 2011).

Entre tanto, se propone hacer las revisiones respectivas de los estudios empíricos realizados para identificar y dar solución a las variables relacionadas entre la herramienta organizacional y su desempeño, así como también corroborar los resultados arrojados de dichas investigaciones. Para tal fin, se establecen tres áreas de estudio respecto a la relación que existe entre la PE y el desempeño en las pymes. La primera hace referencia a la estructura de proyección: hacia dónde se dirige la organización; la segunda se enfoca al procedimiento metodológico para su implementación; y la tercera muestra el impacto que genera la aplicación en las organizaciones (López Salazar, 2005).

En el momento de tener claridad en el concepto teórico, resultado de la investigación empírica, es preciso conocer cómo se da la PE en las organizaciones. Para dar respuesta a este interrogante, Nikulin y Becker (2015), exponen en su estudio una metodología para el establecimiento de la herramienta en una organización y enfatizan que es necesario realizar un análisis estratégico como un proceso donde la capacidad analítica, técnica, el conocimiento y la intuición son elementos 
imprescindibles. Esto implica una comprensión del ámbito externo donde opera la empresa, conocer cuáles son sus clientes, su competencia, como también las oportunidades y amenazas que le ofrece este entorno externo. En el contexto de las pymes no se evidencia la implementación de la PE de manera formal, se da de forma implícita e intuitiva (Castaño Ramírez, 2011). A pesar de los avances en innovación y la inserción de las nuevas tecnologías, se sigue trabajando en la informalidad, adoptando un enfoque cultural (Vélez-Salazar \& Duque-Osorio, 2017).

Los empresarios direccionan las actividades administrativas a los objetivos propuestos con flexibilidad, adaptándose a los cambios. No obstante, cuando se incrementa la participación en el mercado, el potencial de crecimiento y la posición competitiva relativa se ven en la necesidad de formalizarse administrativamente a partir de la implementación de un proceso de PE en busca de alcanzar mayores resultados que les posibilite permanecer en un determinado mercado. Sin embargo, se argumenta que en la actualidad las pymes que desean alcanzar altos niveles de competitividad y sostenerse en el mercado ven en ésta, no sólo una herramienta que les permite alcanzar el éxito por medio del cumplimiento de sus objetivos a través de la implementación de la estrategia y la ejecución de los planes de acción, sino como metodología de aprendizaje para el personal administrativo (Serrano Cárdenas et al., 2013). Partiendo del principio que son las personas involucradas en los procesos corporativos los que llevan a cabo los planes propuestos por la dirección, optimizando los recursos y generando valor para los clientes. En el mismo sentido, analógicamente hablando, la planeación es a la estrategia como la visión es a la misión. Estos conceptos son inseparables ya que los planes sin acción carecen de objetividad.

\section{El sector confección en Antioquia y su importancia en la implementación de planeación estratégica en las pymes}

La cadena productiva textil-confección es de gran importancia en Colombia, pues representa el $9 \%$ de la producción total industrial para este sector, del cual el 30\% se exporta (Carmona L. \& Gil Quintero, 2008). La contribución de la confección a la economía antioqueña es muy significativa, su fuerza laboral industrial está representada en un 41\%, distribuido así: $18 \%$ textil y $23 \%$ confección (Restrepo Morales \& Vanegas, 2010). Según la Cámara de Comercio de Medellín para Antioquia ([CCMA], 2009), se estima que el tejido empresarial que se ubica en el clúster textil/confección, diseño y moda para el departamento, está constituido por 11.960 empresas con activos totales por cerca de USD 2.765 millones. De acuerdo a las industrias analizadas localizadas en Antioquia, los empleos generados se clasifican por eslabones. Aquellos que agrupan el mayor número de funcionarios son: producción de textiles, confecciones, acabados, comercialización de confecciones y maquila (CCMA, 2009). Según la Encuesta Anual Manufacturera 2017 (en adelante EAM), es el sector nacional que lidera el grupo industrial con un $10.3 \%$ de participación en cuanto a personal ocupado (Departamento Administrativo Nacional de Estadística [DANE], 2017).

Para el departamento los resultados no son favorables respecto a la productividad laboral. De acuerdo a la EAM 2015, de los 21 departamentos encuestados, Antioquia ocupa el lugar número 15 en orden ascendente con menor resultado, representando el $48.5 \%$, superado por Bolívar y Atlántico con $129.1 \%$ y $97.5 \%$, respectivamente. Este factor está medido principalmente por capacidades propias del trabajador, nivel educativo, experiencia, trayectoria en su actividad, condiciones del proceso productivo y de infraestructura de la empresa (Colombia Productiva, 2018). Por su parte, para el caso de Medellín, la ciudad concentra el $60 \%$ de la industria textil. Así, continúa pionera en el 
país en la producción textil y confección con una participación en las exportaciones no tradicionales del $65 \%$ y del $2 \%$ de las exportaciones totales. Además, representa el $1.4 \%$ del producto interno bruto (PIB) y el $1.7 \%$ del PIB manufacturero. En concreto, ésta es una actividad dominante en la economía antioqueña (Rodríguez Ruiz, 2013).

En cuanto a la estructura empresarial, y en relación a los resultados de la encuesta panel de micro establecimientos aplicada a 33.013 unidades productivas que desarrollan actividades económicas de acuerdo a CIIU Rev.4 (clasificación de actividades económicas por procesos productivos que ordena unidades estadísticas con base en su actividad económica principal), 20.086 pertenecen al sector comercio, 9.667 al sector servicios y 3.260 a la industria (DANE, 2017a). En la misma dirección, comercio es pionero con una participación de 38.2\%; la industria manufacturera ocupa el segundo lugar con un $13 \%$, seguido de servicios con un $12 \%$ (CCMA, 2019). En este sentido, según la EAM, para el 2015, concluye que las pymes representan el 66\% del total de empresas del sector de manufactura y generan el 56\% del total de la producción nacional (Colombia Productiva, 2018). De este último, el valor aportado por Antioquia es de 17.9\% y la participación de las pymes en confección de prendas de vestir a nivel nacional es del 53\%. Para el caso del departamento es del 5.4\%. Existen 48 pymes por cada gran empresa dedicadas a este subsector.

En el 2017, Antioquia contaba con 19.572 establecimientos, el 99.3\% pertenecen a pymes y sólo el $0.7 \%$ a empresas grandes, de ellos el $72 \%$ están ubicados en el valle de Aburrá, el $9 \%$ en el oriente y el $5 \%$ en Urabá. Para estas subregiones, por cada 1.000 habitantes hay 37, 30 y 14 empresas, respectivamente (CCMA, 2019), lo que indica que el tejido empresarial en las subregiones es débil con respecto a la capital y los municipios de esta jurisdicción y, por consiguiente, la poca generación de empleo y la baja contribución a las finanzas municipales en el rubro de industria y comercio. Sumado a esto, para el caso específico del oriente, según la Corporación Autónoma Regional de las Cuencas de los Ríos Negro y Nare ([CORNARE], 2014), el desarrollo industrial ha traído efectos positivos como el empleo y la generación de ingresos municipales, aun así, ha generado consecuencias no favorables para el medio ambiente por la alta demanda de recursos naturales de la región.

En cuanto a la importancia en la implementación de procesos de PE por parte de las pymes del sector, es fundamental y transversal a sus procesos. Resulta ser una herramienta funcional para las organizaciones, permitiéndoles adquirir y desarrollar conocimiento a partir de su puesta en marcha (Casas et al., 2020), y más cuando el constante cambio del entorno donde está inmerso el sector productivo representado por las pymes, obliga a que sus dirigentes continúen en permanente actualización de sus procesos administrativos y gerenciales, garantizando, en mayor tiempo, la sostenibilidad en el mercado empresarial (Madrigal Moreno et al., 2015).

Lo anterior cobra importancia si la dirección comprende que la adaptación de su modelo productivo a la estructura de una herramienta administrativa le permite identificar un panorama completo de la tendencia de la empresa en todos los aspectos para tomar decisiones de gran impacto tendientes a lograr la sostenibilidad a largo plazo y así desarrollar planes efectivos, esperando un resultado promisorio en el futuro (Kamariotou \& Kitsios, 2019).

En este sentido, la relación de las pymes con esta herramienta, más que importante, resulta útil, en parte por el tamaño y la estructura administrativa desde un enfoque macro. De ahí que las unidades 
productivas bajo este modelo se convierten en el escenario ideal para la estructuración de metodologías dinámicas de planeación, desde la incorporación de la estrategia como motor dinamizador para la toma de decisiones, hasta la integración de aspectos tácticos y operativos.

Así la pyme, aparte de su formalización e incursión en el mercado, deberá, para el logro de su permanencia y el nivel de competitividad requerido por el entorno empresarial donde se encuentra inmersa, formular la misión, la cual define la consolidación de su razón de ser en el contexto de su línea de operación, y está enmarcada en la calidad y en el desarrollo humano y sostenible. Por su parte, la visión es el establecimiento de la proyección a futuro de la empresa en sus diversas líneas de negocio, además de la incorporación de los demás lineamientos misionales que representen su identidad. En relación al enfoque estratégico se requiere el establecimiento de objetivos y estrategias con un análisis profundo de variables externas y de cada uno de sus procesos internos para la ejecución de planes de acción que direccionan a la pyme al logro de un índice de competitividad que se ve reflejado en el incremento de rentabilidad, efectividad y sostenibilidad en el mercado.

Para este fin, el estudio de caso con el cual se investigan los fenómenos en un contexto real, Villarreal Larrinaga y Landeta Rodríguez, (2010) proponen adoptar una metodología de PE para evaluarla en una pyme que conlleve a definir objetivos estratégicos y proyectar líneas generales de acción, direccionando a la empresa a posicionarse en el mercado ante el escenario de constantes cambios que presenta esta tipología de empresas, perteneciente en particular al sector textil confección que, en función a su comportamiento, representa mayor índice de competitividad con respecto a otros sectores de la economía.

\section{METODOLOGÍA}

Para la presente investigación se realiza un tipo de estudio mixto cuantitativo - cualitativo de corte transversal (Mann, 2003) debido a que los datos se recolectaron en un único periodo, de junio a diciembre de 2016. La investigación se desarrolló en dos partes. En la primera se realizó un estudio descriptivo donde se identificaron los principales factores asociados a la implementación del proceso de PE en la pyme. Se ejecutó la fase I de la metodología de evaluación propuesta (Figura 2). Según Ugalde Binda y Balbastre-Benavent (2013), los estudios de corte cuantitativo son utilizados, en gran medida, cuando se requiere demostrar fenómenos de causa y efecto. El lenguaje unificado es fundamental en este modelo y los fenómenos estudiados deben ser objeto de fácil cuantificación.

En la segunda parte, como técnicas para la recolección de la información, se utilizaron entrevistas semiestructuradas de enfoque cualitativo y la observación directa en la evaluación de los efectos de la metodología «herramientas para la planeación estratégica en las microempresas» (Vargas Vallecilla, 2008), aplicada a una pyme del sector confección. Se llevaron a cabo las fases II y III (Figura 2). Según Vasilachis de Gialdino (2006), la investigación cualitativa es predominante para indagar en situaciones naturales, intentando dar sentido o interpretar los fenómenos en los términos del significado que las personas les otorgan. En la misma dirección, Alonso et al., (2017) sostienen que en este tipo de investigación se establecen diversos procedimientos en la generación de observaciones que son registradas y, una vez analizadas, se aplican los resultados con base a su alcance. 
Para alcanzar el objetivo planeado, se realizó una revisión documental para consultar, extraer y recopilar la información (Calle, 2016) en la identificación de los diferentes modelos para la aplicación de la herramienta organizacional. Se efectuó el proceso de búsqueda de la pyme y del sector de la economía con un alto grado de adaptabilidad y pertinencia al campo de la investigación para hacer posible su implementación. El desarrollo metodológico para la evaluación de la herramienta se ejecutó en 3 fases. En la Figura 2 se presenta de forma detalla la metodología de evaluación propuesta:

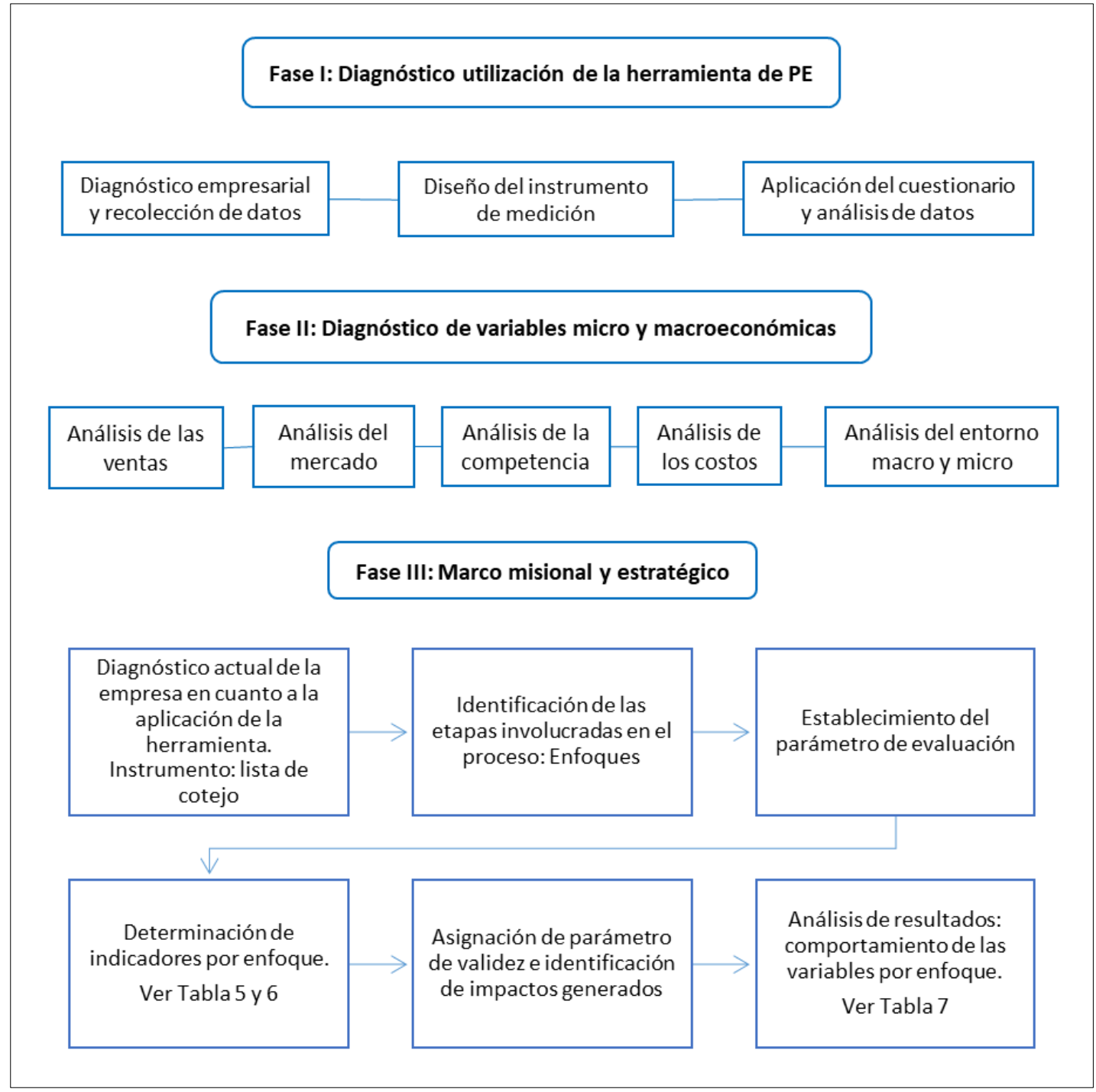

Figura 2. Metodología de evaluación planeación estratégica

Figure 2. Methodology to evaluate strategic planning

Fuente: elaboración propia a partir de (Vargas Vallecilla, 2008).

Fase I. Diagnóstico acerca de la utilización de la herramienta de PE

Esta fase tuvo como objetivo definir las principales causas asociadas a la implementación del proceso de PE en la pyme. Además, se divide en las siguientes etapas. 


\section{Diagnóstico empresarial inicial y recolección de datos}

Esta etapa tuvo lugar en la empresa. Se realizaron visitas periódicas durante un mes para la recolección de la información y se conoció de primera mano, por medio de preguntas diagnósticas realizadas tanto al personal directivo como al operativo, el micro y macro entorno económico y empresarial de la pyme, lo que permitió el diseño de una base datos. Como instrumento se utilizó una escala de Likert de 5 puntos: definitivamente sí, probablemente sí, indeciso, probablemente no, definitivamente no.

\section{Diseño del instrumento de medición}

Una vez clasificada la información, se dio lugar al diseño de la encuesta que se denominó «Percepción PE» que en total fueron 25 ítems, de los cuales 1 fue una pregunta clave para conocer si se había implementado en la pyme procesos de PE. Los demás se agruparon en 4 bloques: i) importancia de la implementación de la PE, ii) realización de estudios administrativos, iii) consecuencias de no implementar procesos de PE, iv) grado de implementación de PE en la pyme. Las respuestas se midieron mediante las escalas de Likert de 5 puntos: totalmente de acuerdo, de acuerdo, ni de acuerdo ni en desacuerdo, en desacuerdo, totalmente en desacuerdo. Completamente verdadero, verdadero, ni verdadero ni falso, falso, completamente falso.

\section{Aplicación del cuestionario y análisis de datos}

Mediante el proceso de entrevistas se realizó la encuesta a 28 empleados durante un mes, se clasificó el personal en 6 grupos y de acuerdo a su programación laboral se asignó la fecha para la aplicación del cuestionario. Una vez analizados y procesados los datos se clasificaron como factores, los cuales fueron sometidos a la valoración establecida por Mora-Riapira et al., (2015) para conocer su nivel de importancia respecto a la implementación del proceso de PE.

\section{Fase II. Diagnóstico de variables micro y macroeconómicas}

Se establece la guía para realizar el análisis de la situación actual de la empresa respecto al entorno micro y macroeconómico. Se evaluaron los numerales del 1 al 5 de la metodología objeto de estudio.

\section{Análisis de las ventas}

Para esta etapa fue necesario consultar los estados financieros elaborados bajo las Normas Internacionales de Información Financiera (NIIF) (en Colombia se ha establecido que los marcos técnicos normativos son aplicables a todo tipo de entidades obligadas a llevar contabilidad. Para el caso de las cooperativas, pueden pertenecer a cualquiera de los tres grupos y por consiguiente aplicar las NIIF, la NIIF para las PYMES o la NIIF para microempresas). Para este análisis la empresa proporcionó el acceso al software contable siigo, a través del cual se obtuvo el estado de resultados integral (ERI), incluido en las NIIF, mediante el cual se mide el desempeño financiero. De igual forma, del mismo software se obtuvo el estado de situación financiera (ESF), el cual permite realizar, mediante las cuentas reales, un análisis de la estructura financiera de una organización (Consejo Técnico de la Contaduría Pública [CTCP], 2015). De este último se clasificaron las ventas por cliente, 
ciudad, producto y vendedor para los periodos 2015 - 2018 y se estableció como herramienta de evaluación un análisis comparativo para observar el comportamiento de la variable en ambos años.

\section{Análisis del mercado}

Se diseñó un cuestionario tomando las 12 preguntas establecidas en la metodología y utilizando como referencia la base de datos mencionada en la etapa 3. Posteriormente, se conformó un grupo de 6 directivos de la empresa y durante 3 semanas, mediante visitas periódicas se realizaron entrevistas a empleados y directivos. Una vez obtenido los resultados de éste, se procedió a la elaboración de la segmentación del mercado y, realizando un contraste de ésta con las respuestas del cuestionario, se consolidaron las respuestas a los 12 interrogantes descritos en esta etapa.

\section{Análisis de la competencia}

La empresa contaba con una base de datos con 147 empresas identificadas, ubicadas en el área metropolitana del Valle de Aburrá y el oriente antioqueño. Se tomó esta información y se realizó la verificación en la superintendencia de sociedades y las cámaras de comercio de Medellín y del oriente antioqueño, de allí se obtuvo información básica de acuerdo a su composición, clasificación y demás variables como: ubicación, productos y servicios, mano de obra, participación en el mercado. Como instrumento para realizar los cálculos estadísticos y la emisión de reportes se utilizó el software siigo, lo que originó una base de datos más robusta y permitió delimitar su competencia directa en ambas zonas de influencia.

\section{Análisis de costos}

Se realizó la comparación de los costos, ventas y utilidad para los años 2015 y 2018 en los 4 primeros meses del año, tomando como referencia la relación de ventas y costos. Como instrumento para el cálculo, el análisis, las proyecciones y gráficos se utilizó el software siigo.

\section{Análisis del entorno macro y micro}

Para el diseño de la matriz DOFA, en la generación de las estrategias corporativas, se tuvo en cuenta, entre otros estudios, el de Nikulin y Becker (2015), cuya estructura fue adaptada de acuerdo a los cambios del entorno del cluster textil confección. Con la información obtenida resultado del diagnóstico inicial elaborado en la etapa 3, se realizó la definición, clasificacion, analisis y el cruce las de variables internas (fortalezas - debilidades) y externas (oportunidades - amenazas) y se establecieron las estrategias.

\section{Fase III: Marco misional y estratégico}

Se presenta el proceso de evaluación a los numerales del 6 al 9 de la metodología, que comprende: la misión, visión, objetivos estratégicos, estrategia de la organización y planes de trabajo. 


\section{Diseño e implementación de metodología}

Se tomó toda la información resultado de los procesos de PE implementados por la pyme en los periodos 2000 - 2015 y 2016 - 2021, se diseñó la metodología, se ejecutó el proceso utilizando el instrumento de evaluación y, posteriormente, mediante un análisis comparativo se presentaron los resultados.

\section{RESULTADOS}

Con la aplicación del cuestionario «Percepción PE» se conoció la perspectiva del personal de la pyme referente a la implementación de la herramienta, se identificaron los factores asociados a la ejecución del proceso de PE y se analizó su estado actual por medio de los resultados. El grado de importancia de cada factor es medido en una escala de $0 \%$ a 100\% con la interpretación:

Muy bajo: 0 - 20

Bajo: $21-40$

Mediano: $41-60$

Alto: $61-80$

Muy alto: $81-100$

Del total de 16 factores identificados, como factor predominante, el $85.8 \%$ de los encuestados afirmaron que los elevados niveles de producción limitan el tiempo que se puede emplear para su implementación. En cuanto a no tener claro los objetivos y la estrategia corporativa, el 78.6\% indicaron que es un factor indispensable en el establecimiento de una estructura jerárquica administrativa, y la falta de ello se interpreta como no tener las bases iniciales para el proceso de planeación.

Además, el $75 \%$ del personal identificó que los factores que influyen de forma directa en la no implementación se describen así: no se han realizado estudios administrativos dado su carácter informal, representa un gasto considerable de tiempo y dinero y finalmente se presenta carencia de facilidad y practicidad para su aplicación en un alto grado.

Los factores que presentaron mayor incertidumbre para el $67.9 \%$ de los encuestados es que no cuente con los recursos físicos, humanos y financieros, y más aún, que el proceso de planeación se construya y no se ejecute. Por otro lado, el $64.3 \%$ percibieron que el personal directivo y administrativo desconoce herramientas eficaces y dinámicas para la estructuración organizacional y que el personal no cuenta con las competencias necesarias para llevar a cabo un proceso de PE, al igual que no tiene definido la razón de ser de la empresa y ésta no se proyecta a futuro, estos dos últimos factores representaron el $60.8 \%$ de la muestra. Por el lado de la existencia de problemas operacionales y administrativos, se observa que el $57.1 \%$ indicaron la presencia de ellos en la pyme.

La percepción del $53.5 \%$ con respecto al desconocimiento administrativo y operacional se ve reflejado en la informalidad y en el proceso empírico e intuitivo de desarrollar el proceso administrativo. Con un $46.4 \%$ se interpretó, concretamente, que la organización carece de una estructura administrativa definida. Finalmente, los factores que obtuvieron un menor valor en los 
resultados, representados por el $10.7 \%$ y el $32.2 \%$, respectivamente, son: se considera útil pero no necesaria para operar con normalidad y la aplicación no representa verdadera importancia para la empresa. En la Tabla 1 se clasifican los factores identificados de PE, resultado de la encuesta de acuerdo a la escala de importancia, y se presenta los datos porcentuales por cada aspecto.

Tabla 1. Categorización factores de planeación estratégica

Table 1. Categorization of strategic planning factors

\begin{tabular}{|c|c|c|c|c|c|c|c|c|c|}
\hline Factor & $\begin{array}{c}{ }^{1} \text { Muy bajo } \\
0-20 \\
\end{array}$ & Factor & $\begin{array}{c}\text { Bajo } \\
21-40\end{array}$ & Factor & $\begin{array}{c}\text { Mediano } \\
41-60\end{array}$ & Factor & $\begin{array}{c}\text { Alto } \\
61-80\end{array}$ & Factor & $\begin{array}{l}\text { Muy alto } \\
81-100\end{array}$ \\
\hline \multirow[t]{7}{*}{1} & ${ }^{2} 10.7$ & 2 & 32.2 & 3 & 46.4 & 8 & 64.3 & 16 & 85.8 \\
\hline & & & & 4 & 53.5 & $9-10$ & 67.9 & & \\
\hline & & & & 5 & 57.1 & 11 & \multirow{4}{*}{75} & & \\
\hline & & & & $6-7$ & 60.8 & 12 & & & \\
\hline & & & & & & 13 & & & \\
\hline & & & & & & 14 & & & \\
\hline & & & & & & 15 & 78.6 & & \\
\hline
\end{tabular}

Fuente: elaboración propia. ${ }^{1}$ Escala de valoración, ${ }^{2}$ datos en porcentajes.

Para evaluar los numerales del 1 al 5 de la metodología en la pyme seleccionada, fue necesario recolectar información suministrada por la empresa. Se muestran los resultados obtenidos después de haber realizado los análisis respectivos para cada uno de los numerales, los cuales se presentan descritos:

Análisis de la situación actual en los estados financieros (estado de situación financiera - estado de resultados integral 2015 - 2018). Numeral 1

La pyme pertenece al sector cooperativo y, según ley 79 de 1988, puede tener diversas líneas de negocio dado su figura legal. Para este caso se realizó análisis de la información contable contenida en los estados financieros y se presentó la información de las tres actividades económicas que en la actualidad ejerce: i) servicio de confección industrial, ii) comercialización productos de consumo, iii) corresponsal bancario, para los años 2015 - 2018. El servicio i) en el primer año se presta a dos empresas, las cuales se denominaron A y B y en el segundo año a las empresas C, D y E. El servicio de maquila opera en la planta de producción. Los servicios ii) y iii), por ser actividad comercial se prestan en el punto de venta de la empresa.

De acuerdo a la metodología y siguiendo su orden en el numeral 1, se analizó la variable ventas descrita en el estado de resultados integral. Se presentó también la variable costos. De éste se mostraron los datos de la utilidad neta en los periodos descritos, además, se obtuvo el estado de situación financiera facilitando el análisis a las cuentas activo, pasivo y patrimonio y se conocieron los estados financieros actuales. Más los impactos generados después de la implementación de la herramienta (Tabla 7) y los resultados presentados en el periodo 2016 - 2021 (Tabla 6), se observó que a nivel financiero hubo incremento de la rentabilidad $y$, en consecuencia, sostenibilidad en el mercado una vez la empresa cuenta con una estructura organizacional definida. 
Por lo anterior, se realizó análisis macro de las ventas, más la herramienta metodológica establece la importancia del análisis individual y categórico de esta variable, en relación a ello se tomaron las ventas generales para los años 2015 - 2018 y se realizó la clasificación por cliente, ciudad, producto y vendedor y con los totales se hizo comparación en ambos años. El incremento del primer periodo con respecto al segundo es de $0.0110 \%$, evidenciando que la representación en ventas fue mayor en el 2015.

\section{Análisis del mercado. Numeral 2}

Uno de los puntos evaluados en la pyme, en uso de la herramienta metodológica de PE, fue el mercado. Se identificaron los parámetros utilizados por el autor y se hizo el respectivo análisis. Se evidenció que lo que se propone es establecer el mercado objetivo de la empresa. En este sentido, se realizó una segmentación del mercado orientado a la industria clasificando las variables. Para éste, se utilizan las de tipo: geográficas, demográficas y por comportamiento.

En la Tabla 2 se presenta información que describe de forma específica la segmentación del mercado haciendo una aproximación de respuesta a 6 de las 12 preguntas establecidas: el número 4. ¿Características del mercado? 5. ¿Son clientes/usuarios permanentes? 6. ¿lmportancia del producto? 7. ¿Frecuencia de compra? 9. ¿Por qué eligen los servicios de la pyme? 10. ¿Hay fidelidad del cliente?

Tabla 2. Segmentación del mercado Table 2. Market segmentation

\begin{tabular}{lll}
\hline Geográfico & \multicolumn{1}{c}{ Demográfico } & \multicolumn{1}{c}{ Por Comportamiento } \\
\hline Colombia, Antioquia & $\begin{array}{l}\text { 1Por tamaño: } 96 \text { empleados, rango: } \\
\text { 50-200. (Mediana). }\end{array}$ & $\begin{array}{l}\text { Ocasión de compra: los servicios se } \\
\text { ofrecen durante todo el año y se } \\
\text { incrementa la demanda en temporadas. }\end{array}$ \\
\hline 2Por sus activos expresados en SMLV: & $\begin{array}{l}\text { Beneficios Esperados: maquila confección } \\
\text { industrial bajo parámetros de calidad y } \\
\text { cumplimiento. }\end{array}$ \\
\hline Por sector de la economía: industrial $1.658,65$, rango: $501-5000$. & $\begin{array}{l}\text { Tasa de utilización: según requerimiento } \\
\text { del cliente, niveles de ventas, } \\
\text { disponibilidad en tiempo, recursos } \\
\text { económicos. Los pedidos regularmente } \\
\text { comercial }\end{array}$ & $\begin{array}{l}\text { Lealtad a la empresa: está representada } \\
\text { en la calidad del servicio, el cumplimiento } \\
\text { en la entrega y la capacidad de respuesta } \\
\text { de la planta de producción. }\end{array}$ \\
\hline
\end{tabular}

Fuente: elaboración propia a partir de Mora-Riapira et al., (2015).

Dando respuesta a las preguntas 1. ¿Se tienen clientes? 2. ¿Tamaño del mercado? 3. ¿Crecimiento del mercado por producto?, se realizó comparación en cuanto al crecimiento en el mercado a los clientes A y B que permanecieron vigentes en los años 2015 - 2018. El incremento en ventas, en relación con el total en ambos años para los clientes, fue de un $1 \%$ y $11 \%$, respectivamente. Esto denota que el cliente potencial para la pyme sigue siendo el B, la incorporación de nuevas herramientas y la integración de éstas a los procesos, además de la puesta en marcha de la PE en su enfoque estratégico, la empresa ha logrado incursionar en el mercado de manera progresiva 
obteniendo en 2018 tres clientes: C, D y E, que representan el $9.9 \%$ de incremento en las ventas respecto al total para ese año.

De lo anterior se infiere que los resultados fueron favorables referente a la participación en el mercado después de haber implementado el proceso de $\mathrm{PE}$, específicamente la ejecución de estrategias de mercadeo descritas en los objetivos del enfoque estratégico. En consecuencia, a su desarrollo y seguimiento, ha logrado no sólo adquirir nuevos clientes, sino que, a través de estrategias promocionales y publicitarias, que ejecutándolas y haciéndoles el control respectivo, se ven reflejadas en la organización. En contraste, cabe resaltar que, para este caso, en el ejercicio de comparación de ambos años, el factor económico representado en ventas no fue de crecimiento dado que las ventas en el 2015 fueron superiores en un $0.0110 \%$ con respecto al 2018. En este orden, el resultado está expresado en la adquisición de nuevos clientes, siendo ésta la estrategia eficaz para materializar las herramientas organizacionales, los sistemas de gestión y los procesos que se planean.

Para dar respuesta a las 3 últimas preguntas de las 12 establecidas: la 8. ¿Compras directas o por intermediario? De acuerdo con el modelo de mercadeo adoptado y al prestar servicio de maquila, la empresa contrata directamente con sus clientes, lo que significa que son ellos los encargados de recoger el producto terminado en el punto de fábrica, siendo así un beneficio en doble vía, haciendo negociaciones directas sin afectar los costos de acuerdo a la no presencia de intermediarios, además se agiliza el proceso con respecto a los tiempos de entrega. La 11. ¿Por qué los clientes no eligen el servicio de la empresa? Se puede afirmar que uno de los factores que impide a las empresas a hacer negociación para la prestación del servicio de confección con la pyme es por la distancia que presenta. Los clientes potenciales ubicados en el Valle de Aburrá tienen el $40 \%$ de participación en el mercado y es donde está en mayor proporción la industria textil confección en Antioquia (DANE, 2017a). Finalmente, la 12. ¿Requerimientos específicos del cliente a futuro? Es sin lugar a dudas la modernización de la planta en términos de maquinaria tecnológica que vaya a la vanguardia de los nuevos modelos de fabricación en relación con la cuarta revolución industrial.

\section{Análisis de la competencia. Numeral 3}

Al evaluar este punto, es preciso afirmar que la competencia está representada en 147 empresas dedicadas a la elaboración de prendas de vestir. De ellas, el 68.02\% están ubicadas en Medellín y el $31.97 \%$ en el oriente antioqueño. Del total de esta tipología de empresas, 97 están legalmente constituidas y pertenecen por clasificación según activos y número de empleados a pequeñas y medianas empresas (Mora-Riapira et al., 2015). Cuentan, además, con marca propia, infraestructura, tecnología, maquinaria e insumos suficientes para su operación, excepto el personal, puesto que en la actualidad la oferta de mano de obra calificada para este sector ha disminuido considerablemente. Al ser empresas que prestan el servicio de maquila, sus productos varían según el mercado y su número de clientes, trabajan bajo esquema de áreas funcionales. No obstante, 10 lo hacen bajo enfoque por procesos. De ello se deriva el tamaño en las ventas, el $80 \%$ tienen una estructura organizacional definida, por lo que utilizan estrategias diversas en cuanto a áreas: administrativa, mercadeo, financiera, de producción y de gestión humana que garantiza mayor participación en el mercado, descrito de acuerdo con esta clasificación en un 66\%.

Por consiguiente, los 50 restantes son pequeños talleres de confección que, por clasificación según Mora-Riapira et al., (2015), pertenecen a microempresas con menos de 10 empleados y activos 
totales expresados en SMLV inferiores a 500. Lo cual no representan una competencia significativa por su carencia de estructura administrativa e industrial, así como limitantes en capacidad de producción, número de empleados, volumen de ventas, participación en el mercado, número de clientes, infraestructura y maquinaria, recursos físicos y tecnológicos. Por lo demás, y de acuerdo con el análisis se evidenció el potencial que tiene la región para la reestructuración de las unidades productivas representadas en esta clasificación para su desarrollo y consolidación administrativa en el logro de mayores resultados económicos y de competitividad en el mercado.

\section{Análisis de costos. Numeral 4}

Define la interpretación de esta variable. Se tomó como referencia la relación de ventas y costos para el año 2015 y 2018. En la Tabla 3 se presentaron datos de 4 de los 12 meses laborados y se analizó no sólo los costos, sino también las variables venta neta y utilidad. En las cifras que representan los costos descritos están los de producción y ventas. Haciendo el comparativo de ambos años se observó que, excepto el mes de abril, la utilidad fue superior para el periodo 2018 , definido en un incremento de $1,43 \%$ para el mes de febrero, 0,11\% marzo, 0,52\% abril y 2,96\% mayo, de lo cual se afirma que las utilidades se incrementaron significativamente después de la implementación de la herramienta organizacional, a excepción del mes de abril que fue $7.7 \%$ menos con respecto al año 2015. Cabe resaltar que en este punto se expresa el incremento parcial en las utilidades, no en las ventas, debido a que se hace el análisis mensual, lo que es diferente en las ventas para el año 2018 donde no se obtuvo incremento y éstas fueron superiores en el año 2015.

Tabla 3. Relación de ventas y costos $2015^{1}-2018^{2}$

Table 3. Relationship between sales and costs in the $2015^{1}-2018^{2}$ period

\begin{tabular}{ccccc}
\hline \multicolumn{5}{c}{${ }^{1}$ 2015 } \\
\hline Mes & Venta Neta & Costos & Utilidad & \% Utilidad \\
\hline febrero & 83.171 .722 & 73.824 .392 & 9.347 .329 & 11.24 \\
\hline marzo & 95.762 .768 & 83.865 .850 & 11.896 .917 & 12.42 \\
\hline abril & 110.606 .295 & 97.224 .860 & 13.381 .434 & 12.1 \\
\hline mayo & 89.083 .297 & 80.448 .797 & 8.634 .500 & 9.69 \\
\hline \multicolumn{5}{c}{${ }^{2} 2018$} \\
\hline febrero & 77.484 .661 & 67.719 .095 & 9.765 .565 & 12.67 \\
\hline marzo & 110.097 .406 & 96.273 .279 & 13.824 .127 & 12.53 \\
\hline abril & 79.625 .087 & 69.653 .001 & 9.972 .086 & 12.62 \\
\hline mayo & 83.049 .946 & 72.584 .373 & 10.465 .591 & 12.65 \\
\hline Fuente: elaboración propia a partir de relación de ventas y costos de la Pyme. \\
Antes de Implementación PE y ${ }^{2}$ Después de Implementación PE (datos en miles de pesos).
\end{tabular}

\section{Análisis del entorno macro y micro. Numeral 5}

Según el orden, se analizan las variables externas e internas: oportunidades - amenazas, fortalezas debilidades, de la herramienta DOFA aplicada. En total fueron 180 variables identificadas, expresadas así: 47 y 18 externas y 67 y 48 internas. Como resultado de cruzarlas se obtuvo 34 estrategias 
clasificadas en las áreas de: producción, recursos humanos, administrativa, mercadeo, recursos físicos materiales y financiera (Tabla 4).

El cumplimiento de los objetivos es el resultado de la puesta en marcha de las estrategias mediante los planes de acción. En este sentido, y clasificando los objetivos con respecto a la prioridad de cumplimiento de acuerdo a la necesidad de la pyme, se establece que en orden de importancia requiere desarrollar, en principio, aquellos que se encuentran descritos en las estrategias de crecimiento, seguido de los pertenecientes a las estrategias de supervivencia y defensiva, respectivamente.

Tabla 4. Estrategias corporativas por áreas de trabajo

Table 4. Corporate strategies classified by type

\begin{tabular}{|c|c|}
\hline Estrategias (FO) de crecimiento & Estrategias (DO) De Supervivencia \\
\hline 1. Diversificación del portafolio de Servicios & 18. Implementación de un Canal de Comunicación \\
\hline 2. Incremento de alianzas estratégicas & 19. Implementación área de Calidad \\
\hline $\begin{array}{l}\text { 3. Implementación del sistema de gestión de la } \\
\text { calidad ISO 9001, versión } 2015\end{array}$ & 20. Implementación área de Mercadeo \\
\hline $\begin{array}{l}\text { 4. Mejoramiento y cumplimiento del SGSST: (sistema } \\
\text { de gestión de seguridad y salud en el trabajo) }\end{array}$ & $\begin{array}{l}\text { 21. Mejora en comunicación interna y acompañamiento } \\
\text { a los módulos de producción por parte de las áreas de } \\
\text { apoyo }\end{array}$ \\
\hline 5. Aumento en el $\%$ de productividad & $\begin{array}{l}\text { 22. Mejoramiento en la planeación, programación de } \\
\text { producción y utilización del programa existente para el } \\
\text { manejo de tiempos }\end{array}$ \\
\hline $\begin{array}{l}\text { 6. Capacitación a nivel corporativo y universitario } \\
\text { para el personal }\end{array}$ & 23. Reorganización área administrativa \\
\hline $\begin{array}{l}\text { 7. Aumento del conocimiento y mejora de } \\
\text { competencias en el personal }\end{array}$ & 24. Consolidación del equipo directivo \\
\hline 8. Reestructuración de la escala salarial del personal & 25. Generación de mayor capacidad de ingresos \\
\hline 9. Aumento de la participación en el mercado & Estrategias (DA) Alternativas Defensivas \\
\hline 10. Incremento de la rentabilidad & 26. Ejecución análisis de la competencia \\
\hline $\begin{array}{l}\text { 11. Consolidación de las áreas definidas de la } \\
\text { cooperativa }\end{array}$ & 27. Ejecución campañas publicitarias \\
\hline 12. Consecución y adecuación de infraestructura & $\begin{array}{l}\text { 28. Tener previsto la consecución de sede propia o } \\
\text { alquilada }\end{array}$ \\
\hline 13. Implementación área de recursos humanos & $\begin{array}{l}\text { 29. Consecución de clientes y proveedores con mejores } \\
\text { precios }\end{array}$ \\
\hline $\begin{array}{l}\text { 14. Consecución de maquinaria - equipo - } \\
\text { tecnología }\end{array}$ & Estrategias (FA) de Supervivencia \\
\hline $\begin{array}{l}\text { 15. Incremento de innovación y creatividad en los } \\
\text { procesos }\end{array}$ & $\begin{array}{l}\text { 30. Ejecución de alianzas estratégicas con la } \\
\text { competencia a nivel local }\end{array}$ \\
\hline $\begin{array}{l}\text { 16. Establecimiento de visión y responsabilidad } \\
\text { social empresarial }\end{array}$ & $\begin{array}{l}\text { 31. Aumento en la participación en el mercado } \\
\text { obteniendo nuevos clientes fidelizando los existentes }\end{array}$ \\
\hline \multirow[t]{3}{*}{$\begin{array}{l}\text { 17. Incremento en el número de clientes y } \\
\text { proveedores }\end{array}$} & $\begin{array}{l}\text { 32. Disponibilidad de capital disponible o acceder a } \\
\text { fuentes de financiación }\end{array}$ \\
\hline & 33. Vínculo con el sector público \\
\hline & $\begin{array}{l}\text { 34. Disponibilidad de activos disponibles y exportar a } \\
\text { nuevos mercados }\end{array}$ \\
\hline
\end{tabular}

Fuente: elaboración propia. 
Para el periodo 2000 - 2015, se logró identificar que la empresa tenía construido de forma empírica algunos elementos propios de la PE; también se pudo corroborar que a finales del 2015 inició, de manera formal, el proceso de implementación de la PE por lo que estableció la plataforma estratégica para el periodo 2016 - 2021. Lo anterior permitió que la evaluación de la tercera fase en el desarrollo de los numerales del 6 al 9 de la metodología se llevara a cabo en los dos momentos, antes y después de aplicar la herramienta. El proceso de evaluación está descrito en la Figura 2 fase III, donde el parámetro de evaluación establecido se definió en una escala de 1 a 6 , y se determinó que para dar viabilidad a la herramienta el promedio ponderado debe ser $\geq 3$. En la Tabla 5 y Tabla 6, respectivamente, se muestra de forma comparativa los resultados obtenidos de la evaluación, donde se indica la puntuación obtenida de los enfoques: misional, estratégico y estructura organizacional para cada año, así como el valor porcentual de cada una de las variables analizadas en ellos.

Con el análisis de los resultados (Tabla 7), primero se mostró que la herramienta es viable una vez la empresa construye el proceso de planeación, generando impactos positivos para la organización. Posteriormente, la herramienta de evaluación permitió identificar las etapas para la construcción de la PE. Como valor agregado para el componente estratégico, el resultado del análisis previo del entorno macro y micro, numeral 5 fase II, estableció 34 estrategias corporativas por áreas de trabajo (Tabla 4) con las cuales se trazaron los objetivos estratégicos y los planes de acción.

Tabla 5. Análisis cruzado y calificación de enfoques 2000 - 2015

Table 5. Cross-impact analysis and classification of approaches in the 2000-2015 period

\begin{tabular}{|c|c|c|c|c|c|}
\hline \multicolumn{6}{|c|}{ ANTES DE CONSTRUCCIÓN PE } \\
\hline \multicolumn{6}{|c|}{ Período 2000 - 2015} \\
\hline $\begin{array}{l}\text { Enfoque } \\
\text { misional }\end{array}$ & \multicolumn{3}{|c|}{ Enfoque estratégico } & \multicolumn{2}{|c|}{ Estructura organizacional } \\
\hline 1.32 & \multicolumn{3}{|c|}{0.21} & \multicolumn{2}{|c|}{1.11} \\
\hline \multicolumn{6}{|c|}{ Calificación total en escala de 1 a 6: 2,64 } \\
\hline $\mathrm{SI}$ & Parcial & NO & Parcial & $\mathrm{SI}$ & Parcial \\
\hline $33 \%$ & $67 \%$ & $83 \%$ & $17 \%$ & $67 \%$ & $33 \%$ \\
\hline $\begin{array}{l}\text { Valores - } \\
\text { Principios }\end{array}$ & $\begin{array}{l}\text { Misión - } \\
\text { Visión }\end{array}$ & $\begin{array}{c}\text { Pronóstico costos - } \\
\text { ventas }\end{array}$ & $\begin{array}{l}\text { Manual de } \\
\text { funciones }\end{array}$ & $\begin{array}{c}\text { Empresa } \\
\text { legalmente } \\
\text { constituida }\end{array}$ & $\begin{array}{c}\text { Conocimiento de } \\
\text { planeación } \\
\text { estratégica }\end{array}$ \\
\hline \multirow[t]{2}{*}{$\begin{array}{l}\text { Políticas y } \\
\text { código de } \\
\text { ética } \\
\end{array}$} & $\begin{array}{c}\text { Imagen } \\
\text { corporativa }\end{array}$ & $\begin{array}{l}\text { Análisis de } \\
\text { competencia }\end{array}$ & & $\begin{array}{c}\text { Representación } \\
\text { legal }\end{array}$ & Organigrama \\
\hline & & $\begin{array}{c}\text { Objetivos, } \\
\text { estrategias y planes } \\
\text { de acción }\end{array}$ & & & \\
\hline
\end{tabular}


Tabla 6. Análisis cruzado y calificación de enfoques periodo 2016 - 2021

Table 6. Cross-impact analysis and classification of approaches in the 2016-2021 period

\begin{tabular}{|c|c|c|c|}
\hline \multicolumn{4}{|c|}{ DESPUÉS DE CONSTRUCCIÓN PE } \\
\hline \multicolumn{4}{|c|}{ Período 2016 - 2021} \\
\hline Enfoque misional & \multicolumn{2}{|c|}{ Enfoque estratégico } & Estructura organizacional \\
\hline 2.04 & \multicolumn{2}{|c|}{2.04} & 1.38 \\
\hline \multicolumn{4}{|c|}{ Calificación total en escala de 1 a 6: 5,46 } \\
\hline $\mathrm{SI}$ & $\mathrm{SI}$ & Parcial & $\mathrm{SI}$ \\
\hline $100 \%$ & $50 \%$ & $50 \%$ & $100 \%$ \\
\hline Misión y Visión & $\begin{array}{c}\text { Objetivos, estrategias y } \\
\text { planes de acción }\end{array}$ & $\begin{array}{l}\text { Pronóstico de } \\
\text { costos y ventas }\end{array}$ & $\begin{array}{c}\text { Conocimiento de planeación } \\
\text { estratégica }\end{array}$ \\
\hline Valores y Principios & $\begin{array}{c}\text { Mecanismos de } \\
\text { comunicación }\end{array}$ & $\begin{array}{c}\text { Análisis de } \\
\text { competencia }\end{array}$ & Empresa legalmente constituida \\
\hline \multirow[t]{3}{*}{ Imagen corporativa } & & $\begin{array}{c}\text { análisis del } \\
\text { mercado }\end{array}$ & Representación legal \\
\hline & & & Manual de funciones \\
\hline & & & Organigrama \\
\hline
\end{tabular}

Fuente: elaboración propia.

Tabla 7. Análisis de resultados

Table 7. Result analysis

\begin{tabular}{|c|c|c|c|c|c|c|c|c|c|}
\hline Enfoque & $\begin{array}{c}\text { Puntaje } \\
\text { Antes PE }\end{array}$ & $\begin{array}{c}\text { Puntaje } \\
\text { Después } \\
\text { PE }\end{array}$ & Difiere & $\begin{array}{c}\% \\
\text { Antes } \\
\text { de PE } \\
\end{array}$ & $\begin{array}{c}\% \\
\text { Después } \\
\text { de PE } \\
\end{array}$ & $\begin{array}{c}\% \\
\text { Incremento }\end{array}$ & $\begin{array}{l}\text { Ante } \\
\text { s PE }\end{array}$ & $\begin{array}{c}\text { Despué } \\
\text { S } \\
\text { PE }\end{array}$ & $\begin{array}{c}\text { Parámetr } \\
\text { o } \\
\text { validez } \\
\end{array}$ \\
\hline Misional & 1.32 & 2.04 & 0.72 & 0.33 & 1 & 0.67 & \multirow{3}{*}{2.64} & \multirow{3}{*}{5.46} & \multirow{3}{*}{3} \\
\hline Estratégico & 0.21 & 2.04 & 1.83 & 0.17 & 0.5 & 0.33 & & & \\
\hline $\begin{array}{c}\text { Estructura } \\
\text { organizacional }\end{array}$ & 1.11 & 1.38 & 0.27 & 0.67 & 1 & 0.33 & & & \\
\hline
\end{tabular}

i) Identidad, proyección y posicionamiento a nivel de productividad y competitividad.

ii) Participación en el mercado y potencial de crecimiento

iii) Consolidación de la empresa a nivel legal y fiscal

Fuente: elaboración propia.

\section{DISCUSIÓN}

Teniendo como base que las herramientas organizacionales direccionan las pymes a hacer una reestructuración en su modelo administrativo, económico y productivo de forma que los resultados sean favorables, éstas deben ser desarrolladas bajo una metodología idónea, dinámica, eficaz y real, que se pueda materializar. En efecto, en este caso, para lograr que alcance niveles de madurez, solidez y competitividad a nivel regional en el clúster textil confección, es de suma importancia no sólo conocer la metodología apropiada de planeación o la importancia que ésta trae al ser implementada, es establecer el modelo más ideal de acuerdo a la particularidad en términos de administración y producción. La productividad, competitividad y rentabilidad se mejoran en la 
medida que se genere valor a los procesos, realizando transformación constante en ellos por medio de la innovación (Batra et al., 2018). Es así como se hace necesario que los directivos adopten estas herramientas como filosofía, y dispongan sus recursos como inversión para el crecimiento organizacional.

Al hablar de evaluación de metodologías de PE como estudios de caso, aplicados en una organización o en un sector de la economía en particular, se puede referenciar la investigación realizada por Nikulin y Becker (2015) «Una metodología sistémica y creativa para la gestión estratégica: caso de estudio región Atacama - Chile», en la cual se integran los métodos estratégicos: cadena de valor de Porter, PESTA (Político, Económico, Sociocultural, Tecnológico y Ambiental), y la matriz DOFA para la formulación de la PE, con la herramienta teoría de resolución de problemas TRIZ (Teoría para Resolver Problemas de Inventiva), además describe herramientas como: diagrama Abell, matriz PEEA (Posición Estratégica y Evaluación de la Acción), cuadro de mando integral BSC, Boston Consulting Group (BCG), modelo de 7s Mckenzie, y análisis VRIO (Valioso, Raro, Inimitable y Organizado), que son aplicadas en la construcción de los distintos niveles de gestión estratégica: formulación, implementación y evaluación.

En contraste con este estudio, es importante dar a conocer que la metodología de planeación empleada para la evaluación sólo presenta la matriz DOFA como instrumento de análisis en la clasificación de variables externas e internas para la formulación de estrategias y objetivos estratégicos, y carece de herramientas para la elaboración del enfoque misional, así como indicadores de desempeño para el control y la medición de los resultados. Sin embargo, cabe resaltar que como factor diferenciador presenta un desarrollo metodológico estructurado para el proceso de evaluación de herramientas de PE en las pymes.

El estudio buscaba evaluar la aplicabilidad de la herramienta en una industria chilena del sector minero y, según la Corporación de Fomento a la Producción (CORFO) (Nikulin \& Becker, 2015), los resultados de la evaluación metodológica en el clúster minero de Atacama Chile fueron favorables, y su afirmación radica principalmente porque es de fácil utilización y permite establecer estrategias referente a su micro entorno y respecto a infraestructura, recursos humanos, capacidad tecnológica, logística, operaciones, comercialización y marketing. Por otro lado, en el proceso de generación de estrategias se identifican sus parámetros críticos y, por último, se formularon estrategias efectivas para la generación del cambio mediante la propuesta basada en TRIZ. En nuestro caso de estudio, la metodología también presenta favorabilidad respecto a su estructura para la construcción tanto del marco estratégico como el misional.

No obstante, para el caso chileno, se presentaron limitaciones en cuanto al impacto que generan las estrategias, esto se debe a la particularidad de la empresa y al estilo de dirección. Sumado a que el sector minero presenta marcada fluctuación en su macro entorno a causa de variables de la dimensión política, económica, social, tecnológica y ambiental, situación que se asemeja a la presente investigación donde, en relación al cambio constante que presentan las pymes, se sugiere la aplicación de metodologías que se adapten en mayor medida a su tipología y funcionamiento.

Otro estudio referente a esta temática se desarrolló en México y consiste en el diseño de una metodología de PE evaluada en una pyme del sector alimentos (Magaña Magaña et al., 2013), y tiene una particularidad en relación a otros estudios de caso, y es que se dan simultáneos: i) los procesos 
de diseño y evaluación metodológica, ii) un estudio de mercado y un taller de PE. En este último se presenta el procedimiento detallado para la elaboración de la misión, objetivos, estrategias y planes de acción, el cual tiene similitud respecto a la metodología utilizada en el presente estudio de caso. Su principal diferencia es que, en nuestro estudio, se propone un análisis macro de su situación actual respecto a variables como: ventas, mercado, competencia, costos y la situación del entorno macro. Aunque para el caso mexicano el modelo empleado no busca evaluar su aplicabilidad en la pyme, por lo que no se evidencia en los resultados su viabilidad, sí se muestran como principales hallazgos, en el proceso de PE, su desarrollo metodológico representado en la descripción de los objetivos estratégicos, las estrategias y planes de acción resultado de la matriz DOFA, así como la declaración de la misión y los valores institucionales. Además, la empresa cuenta con información en el área de mercadeo, resultado del estudio de mercado realizado.

Por su parte, Mejía Argueta et al., (2016) desarrollaron un caso de estudio sobre planeación por escenarios en una empresa del sector servicios en Colombia. Conocer la importancia que tiene el proceso de planeación por escenarios como método estratégico en las empresas, al igual que describir su procedimiento y evaluarlo en una pyme del sector servicios, fue su principal objetivo. Esta herramienta de gestión integral que incluye la planeación estratégica, táctica y operativa (Aktouf \& Suárez, 2012), resulta de gran utilidad debido a que les permite a las organizaciones anticipar planes de acción, mitigar riesgos e identificar variables para la generación de estrategias para, de esta forma, ser más rentables y competitivas. Pese a que en la metodología se incorporan los conceptos de PE y estrategia corporativa, no se establece la estructura misional, ni se evidencian herramientas para su construcción como eje fundamental que soporta la base estratégica en un proceso de gestión organizacional. Como resultado de la evaluación metodológica se identificaron nichos de mercado poco explotados, así como brechas y oportunidades que por medio de planes de acción posibilitan en mayor medida la creación de valor para sus clientes, que, en consecuencia, son fuente de ventaja competitiva.

De hacer la comparación sobre la evaluación de metodologías de PE como estudios de caso, desde la perspectiva del procedimiento, se pudo observar que los autores citados utilizan herramientas metodológicas que presentan, en gran parte de su contenido, homogeneidad en su estructura. No es la excepción para al estudio de caso realizado por Rodríguez Castillo (2010) en el centro de investigaciones del níquel en Cuba, donde presenta una estructura estratégica que incorpora a los componentes estratégico y misional tradicionales, las fases: i) análisis histórico de la organización, en la cual se realiza un recuento de las principales variables microeconómicas y demás factores que tienen incidencia directa en la puesta en marcha de las estrategias. En este punto se presenta una similitud de la metodología de evaluación empleada en la presente investigación, específicamente en la fase análisis de la situación actual numerales del 1 al 5, y ii) análisis de los escenarios, utilizando diversas visiones estructuradas del futuro en la consideración de múltiples entornos en que los planes pueden verse inmersos, la técnica se aplica para la toma de decisiones a largo plazo, las cuales, como consecuencia, generen impacto significativo a las organizaciones (Mejía Argueta et al., 2016).

En este orden, la contribución de la presente investigación estuvo representada en el desarrollo metodológico para la evaluación de herramientas de PE en las pymes, además de la identificación de factores asociados en los procesos de implementación. Por otra parte, desde la perspectiva teórica se realizó un análisis del sector confección en Antioquia y su importancia en la implementación de 
procesos de PE en las pymes. Como factor diferenciador, también se destaca su componente teórico desde la conceptualización, estado del arte y tendencias de la herramienta administrativa.

\section{CONCLUSIONES}

El estudio permitió concluir acerca de las causas asociadas a la implementación del proceso de PE en la pyme. Los factores que arrojaron mayor calificación fueron, respectivamente: elevados niveles de producción limitan el tiempo, no tener claro los objetivos y la estrategia corporativa, su carácter informal, representa un gasto considerable de tiempo y dinero. $Y$ finalmente, los modelos existentes presentan carencia de facilidad y practicidad para su aplicación en un alto grado. En general, la gestión en la planeación no resulta la más adecuada y radica en el desconocimiento de un modelo eficiente y el poco interés directivo.

El estudio se constituye en la evaluación de la metodología desarrollando los numerales descritos, lo que lleva a concluir inicialmente los 5 primeros así: después de la implementación, las ventas (numeral 1) disminuyeron para el segundo año evaluado, siendo así otros factores los que generaron impacto directo en la evaluación, diferente a la variable analizada. Las utilidades son consecuencia de las ventas y definen en gran medida la efectividad de la herramienta y la metodología de aplicación, lo cual, para el estudio de caso, la favorabilidad es mínima. En relación con el numeral 2, plantea como herramienta para analizar el mercado, un listado de doce interrogantes para considerar su respuesta. De acuerdo con el resultado obtenido se sugiere que para evaluar el componente de mercadeo en una pyme resulta efectivo hacer investigación de mercados o un plan de mercadeo integral.

En materia de competencia, en el numeral 3, partiendo de las características de las empresas que resultan competencia directa, el panorama es favorable, empero, se sugiere que los empresarios deben conceder mayor importancia a la fluctuación del mercado referente a las unidades productivas que ejercen su misma actividad, así como en la reestructuración de su modelo operacional integral a través de la innovación y la incorporación de herramientas tecnológicas. Son éstos los componentes que le permiten agregar valor a sus procesos para ser competitiva. Por su parte, en la revisión a los costos (numeral 4) se constató que el aumento en ventas y costos se da antes de la implementación de la PE y el incremento de utilidades y disminución de costos después de su aplicación. Lo que indica que mayores ganancias no significan mayores ingresos.

La evaluación del entorno macro y micro (numeral 5) en la identificación de las variables en la herramienta DOFA, relaciona la cantidad distribuida entre categorías externas e internas. Donde se pudo predecir inicialmente la favorabilidad en el resultado y así con el cruce de éstas se obtuvo las estrategias que llevan intrínsecos los objetivos estratégicos con los cuales se elabora el plan de acción, significando para el estudio el insumo esencial en la construcción del enfoque estratégico de la PE.

El estudio, en la evaluación a los posteriores numerales del 6 al 9, aplicando la metodología como herramienta en la construcción de la PE, arrojó como resultado su validez; sin embargo, y considerando que el estudio es una aproximación a la evaluación de metodologías de PE en empresas 
de esta tipología, se sugiere, de acuerdo con el constante cambio que presentan, la realización de investigaciones que permitan diseñar metodologías que se adapten al modelo actual de las pymes.

En la encuesta realizada a los empleados de la pyme, se detecta una heterogeneidad en sus criterios respecto a los factores asociados en la implementación de procesos de PE en las organizaciones. En esta investigación no fue objeto de estudio los criterios que tuvieron para dar sus respuestas. Se detecta, además, gran riqueza de conocimiento tácito, producto de la experiencia empírica, concerniente a los procesos productivos derivado de su actividad económica. No obstante, se evidencia una carencia significativa respecto a conocimientos de tipo administrativo y gerencial.

En lo referente a nuevas líneas de investigación, se considera consecuente realizar estudios de tipo longitudinal para identificar los cambios que se presentan en las pymes en su contexto actual, en términos de variables micro y macroeconómicas, además para conocer las nuevas tendencias en el diseño, implementación y evaluación de metodologías de PE en esta tipología de empresas, y conocer los impactos generados resultado de su aplicación. Así mismo, se sugiere la realización de mayores estudios cualitativo - cuantitativo con el fin de profundizar en la construcción de nuevas metodologías de la herramienta organizacional.

\section{CONFLICTOS DE INTERÉS}

El autor declara que no presenta conflictos de interés financiero, profesional o personal que pueda influir de forma inapropiada en los resultados obtenidos o las interpretaciones propuestas.

\section{REFERENCIAS}

Aktouf, O.; Suárez, T. (2012). De la estrategia a la planificación operacional. En Administración, Tradición, revisión y renovación (66-83). Pearson Educación.

Alonso, J. C.; Arboleda, A. M.; Rivera-Triviño, A. F.; Mora, D. Y.; Tarazona, R.; Ordoñez-Morales, P. J. (2017). Técnicas de investigación cualitativa de mercados aplicadas al consumidor de fruta en fresco. Estudios Gerenciales, v. 33, n. 145, 412 - 420. https://doi.org/10.1016/j.estger.2017.10.003

Barriga Manrique, E. (2006). Aspectos institucionales, estructura, evolución reciente y situación competitiva de las pymes colombianas. Economía y Finanzas, n. 6-7. URL

Basco, R. (2017). "Where do you want to take your family firm?" A theoretical and empirical exploratory study of family business goals. BRQ Business Research Quarterly, v. 20, n. 1, 28-44. https://doi.org/10.1016/j.brq.2016.07.001

Batra, S.; Sharma, S.; Dixit, M. R.; Vohra, N. (2018). Does strategic planning determine innovation in organizations? A study of Indian SME sector. Australian Journal of Management, v. 43, n. 3, 493513. https://doi.org/10.1177/0312896217734893 
Blomqvist, S.; Halén, M.; Helenius, M. (2015). Connecting Enterprise Architecture with Strategic Planning Processes: Case Study of a Large Nordic Finance Organization, 2015 IEEE 17th Conference on Business Informatics, Libon, 2015, (43-50). https://doi.org/10.1109/CBI.2015.39

Brinckmann, J.; Dew, N.; Read, S.; Mayer-Haug, K.; Grichnik, D. (2019). Of those who plan: A metaanalysis of the relationship between human capital and business planning. Long Range Planning, v. 52, n. 2, 173-188. https://doi.org/10.1016/j.Irp.2018.01.003

Calle, L. A. (2016). Metodologías para hacer la revision de literatura de una investigación. $\underline{\text { URL }}$

Cámara de Comercio de Medellín para Antioquia. (2009). Avances de la Estrategia Cluster en Medellín y Antioquia. Documentos Comunidad Cluster, n. 5. URL

Cámara de Comercio de Medellín para Antioquia. (2019). Perfiles socio económicos de las subregiones de Antioquia. $\underline{\mathrm{URL}}$

Carmona L., R. J.; Gil Quintero, J. D. (2008). Competitividad y retos en la productividad del cluster textil - confección, diseño y moda en Antioquia. Ciencias Estratégicas, v. 16, n. 20, 247-263. URL

Casas M.; Pérez M.; Rojas J.; Alvarez J. (2020) Strategic Planning Model to Improve Competitiveness for Service Industry SMEs Using the Balanced Scorecard. In: Ahram T.; Taiar R.; Colson S.; Choplin A. (Eds).Human Interaction and Emerging Technologies. Springer. https://doi.org/10.1007/978-3-030-25629-6 155

Castaño Ramírez, A. (2010). Planeación y Estrategia: El caso de Productos Alimenticios El Pilón. Punto de Vista, v. 1, n. 2, 97-105. URL

Castaño Ramírez, A. (2011). Planeación estratégica en la Pyme de Bogotá. Orientación al futuro y evasión de la incertidumbre. Contaduría y Administración, n. 235, 147-173. http://dx.doi.org/10.22201/fca.24488410e.2011.423

Cisneros, L.; Ramírez, G.; Hernández, A. (2011). Control en la empresa familiar. AD-MINISTER, n. 18, 49-76. URL

Colombia Productiva. (2018). Informe dinámicas de producción y comercio exterior de pymes manufactureras. URL

Consejo Técnico de la Contaduría Pública. (2015). Convergencia con las normas internacionales de información financiera (NIIF) en Colombia, orientación técnica sobre entidades sin ánimo de lucro. URL

Contreras Sierra, E. R. (2013). El concepto de estrategia como fundamento de la planeación estratégica. Revista Científica Pensamiento y Gestión, n. 35, 152-181. URL

Corporación Autónoma Regional de las Cuencas de los Rios Negro y Nare (2014). Plan de Gestión Ambiental Regional 2013 - 2032. URL 
David, F. R. (2003). Naturaleza de la Dirección Estratégica. En Conceptos de Administración Estratégica (9 ed.) (5 - 19). México: Pearson Educacion S.A.

de Jorge Moreno, J.; Castillo, L. L.; de Zuani Masere, E. (2010). Firm size and entrepreneurial characteristics: evidence from the SME sector in Argentina. Journal of Business Economics and Management, v. 11, n. 2, 259-282. https://doi.org/10.3846/jbem.2010.13

Departamento Administrativo Nacional de Estadística. (2017). Encuesta Anual Manufacturera. URL

Departamento Administrativo Nacional de Estadística. (2017a). Boletín Técnico Microestablecimientos- Micro octubre 2015 - septiembre 2016. URL

Donkor, J.; Donkor, G. N. A.; Kwarteng, C. K. (2018). Strategic planning and performance of SMEs in Ghana: The moderating effect of market dynamism. Asia Pacific Journal of Innovation and Entrepreneurship, v. 12, n. 1, 62-76. https://doi.org/10.1108/APJIE-10-2017-0035

Frantz, E.; Dugan, A.; Hinchberger, K.; Maseth, B.; Al Sharfa, O.; Al-Jaroodi, J. (2017). SMEs: The effects of strategic management. 2017 IEEE Technology and Engineering Management Society Conference, (TEMSCON) Santa Clara, United States, 2017, 388-393. https://doi.org/10.1109/TEMSCON.2017.7998406

Gerstgrasser, O.; Fiedler, M. (2016). Strategic management in small and medium-sized enterprises (SMES). Asia life sciences, v. 25, n. 1, 163-177. URL

Grajales-Gaviria, D. A.; Castellanos-Polo, O. C. (2018). Evaluación del control interno en el proceso de tesorería de las pequeñas y medianas empresas de Medellín. Revista CEA, v. 4, n. 7, 67-83. https://doi.org/10.22430/24223182.760

Haase, H.; Franco, M. (2016). What factors drive performance of small and medium-sized enterprises? European Journal of International Management, v. 10, n. 6, 678-697. https://doi.org/10.1504/EJIM.2016.079527

Kalenatic, D.; Mancera-Méndez, L. H.; Moreno-Valbuena, K. V.; González-Rodríguez, L. J. (2013). Metodología de planeación logística basada en gestión de proyectos y dinámica de sistemas en empresas prestadoras de servicios. Revista Facultad de Ingeniería Universidad de Antioquia, n. 58, 208-218. URL

Kamariotou, M.; Kitsios, F. (2019). Strategic planning and information systems success: Evaluation in greek SMEs. 2019 IEEE 21st Conference on Business Informatics (CBI), Moscow, Russia, 2019, (204-211). https://doi.org/10.1109/CBI.2019.00030

Kotler, P.; Armstrong, G. (2008). Planeación Estratégica de la compañía: Definir el papel del Marketing. En Fundamentos de Marketing (8 ed.) (37-42). Pearson.

Ley 79 de 1988. Por la cual se actualiza la Legislación Cooperativa. 10 de enero de 1989. D.O No. 38.648. URL 
Ley 905 de 2004. Por medio de la cual se modifica la Ley 590 de 2000 sobre promoción del desarrollo de la micro, pequeña y mediana empresa colombiana y se dictan otras disposiciones. 2 de agosto de 2004. D.O. No. 45.628. URL

Ley 1450 de 2011. Por la cual se expide el Plan Nacional de Desarrollo, 2010-2014. 16 de junio de 2011. D.O. No. 48.102. URL

López Salazar, A. (2005). La planeación estratégica en la pequeña y mediana empresa: una revisión bibliográfica. EconoQuantum (Economía y Negocios), v. 2, n. 1, 141-164. URL

Madrigal Moreno, F.; Madrigal Moreno, S.; Guerrero Dávalos, C. (2015). Planeación Estratégica y Gestión del Conocimiento en las pequeñas y medianas empresas (PYMES), Herramienta básica para su permanencia y consolidación. European Scientific Journal, v. 11, n. 31, 139-150. URL

Magaña Magaña, E.; Licón Trillo, L. P.; Kiessling Davison, C. M.; Soto Zapata, M.; Villarreal Ramírez, V. H. (2013). Planeación Estratégica de una empresa familiar de comida rápida. Revista Mexicana de Agronegocios, v. 32, 335-346. URL

Mann, C. J. (2003). Observational research methods. Research design II: cohort, cross sectional, and case-control studies. Emergency Medicine Journal, v. 20, n. 1, 54-60. http://dx.doi.org/10.1136/emj.20.1.54

Marqués, G. D. J.; Gama, C.G (2020). Local Development Platforms (LDP): An operational framework for business development. European Journal of Management and Business Economics, v. 29, n. 1, 97 - 109. https://doi.org/10.1108/EJMBE-06-2019-0110

Mejía Argueta, C.; Agudelo, I.; Soto Cardona, O. C. (2016). Planeación por escenarios: un caso de estudio en una empresa de consultoría logística en Colombia. Estudios Gerenciales, v. 32, n. 138, 96-107. https://doi.org/10.1016/j.estger.2015.12.004

Mora-Riapira, E. H.; Vera-Colina, M. A.; Melgarejo-Molina, Z. A. (2015). Planificación estratégica y niveles de competitividad de las Mipymes del sector comercio en Bogotá. Estudios Gerenciales, v. 31, n. 134, 79-87. https://doi.org/10.1016/i.estger.2014.08.001

Nikulin, C.; Becker, G. (2015). Una metodología sistémica y creativa para la gestión estratégica: caso de estudio región Atacama - Chile. Journal of Technology Manangement \& Innovation, v. 10, n. 2, 127-144. https://doi.org/10.4067/S0718-27242015000200009

Ojha, D.; Patel, P. C.; Sridharan, S. V. (2020). Dynamic strategic planning and firm competitive performance: A conceptualization and an empirical test. International Journal of Production Economics, v. 222, 107509. https://doi.org/10.1016/j.ijpe.2019.09.030

Ortiz García Navas, B.; Donate Manzanares, M. J.; Guadamillas Gómez, F. (2019). El capital social como enfoque teórico en dirección estratégica. Cuadernos de Gestión, v. 19, n. 2, 137-158. https://doi.org/10.5295/cdg.160646bo 
Pla-Barber, J.; Villar, C.; Botella, A. (2017). Why has Caixa Ontinyent survived? An analysis of its business model and strategy. Universia Business Review, n. 54, 18-43. URL

Restrepo Morales, J. A.; Vanegas, J. G. (2010). Competitividad y comercio exterior de las Pymes del sector textil-confecciones del valle de aburrá: incidencia de tipo de cambio. Revista Virtual Católica del Norte, n. 30, 185-204. URL

Rey, C.; Bastons, M. (2018). Three dimensions of effective mission implementation. Long Range Planning, v. 51, n. 4, 580-585. https://doi.org/10.1016/j.Irp.2017.07.002

Rodríguez Castillo, E. (2010). Aplicación de la planeación estratégica en el centro de investigaciones del níquel. Ingeniería Industrial, v. 31, n. 3, 1-6. URL

Rodríguez Ruiz, G. (2013). Competitividad del cluster textil/confección, diseño y moda en Medellín (Trabajo de grado). URL

Serrano Cárdenas, L.; Bravo Ibarra, E.; Amante García, B. (2013). Una metodología innovadora para la planeación estratégica en las universidades. INGE CUC, v. 9, n. 1, 43-63. URL

Tarapuez, E.; Guzmán, B. E.; Parra Hernández, R. (2016). Estrategia e innovación en las Mipymes colombianas ganadoras del premio Innova 2010 - 2013. Estudios Gerenciales, v. 32, n. 139, $170-$ 180. https://doi.org/10.1016/j.estger.2016.01.002

Ugalde Binda, N.; Balbastre-Benavent, F. (2013). Investigación cuantitativa e investigación cualitativa: buscando las ventajas de las diferentes metodologías de investigación. Revista de Ciencias Economicas, v. 31, n. 2, 179-187. URL

Valencia Maldonado, G.; Erazo, M. A. (2016). El reto de la planificación estratégica en las Pymes. Revista Publicando, v. 3, n. 8, 335-344. URL

Vargas Vallecilla, R. (2008). Herramientas para la planeación estratégica en microempresas. Panorama, v. 2, n. 4, 13-17. http://dx.doi.org/10.15765/pnrm.v2i4.260

Vasilachis de Gialdino, I. (2006). La investigación cualitativa. En Vasilachis de Gialdino, I., Estrategias de investigación cualitativa (24 - 66). Gedisa Editorial.

Vélez-Salazar, F. M.; Duque-Osorio, G. A. (2017). Gestión de una comunidad de práctica. Caso de estudio: incidentes de infraestructura de dos pymes de la ciudad de Medellín. Revista CEA, v. 3, n. 5, 59-68. https://doi.org/10.22430/24223182.649

Villarreal Larrinaga, O.; Landeta Rodríguez, J. (2010). El estudio de casos como metodología de investigación científica en dirección y economía de la empresa. Una aplicación a la internacionalización. Investigaciones Europeas de Direccion y Economia de La Empresa, v. 16, n. 3, 31-52. https://doi.org/10.1016/S1135-2523(12)60033-1 